http://dx.doi.org/10.14393/HeP-v30n57-2017-12

\title{
LENDO MANUSCRITOS COLONIAIS: UMA ANÁLISE CRÍTICA DE TRÊS DOCUMENTOS SETECENTISTAS SOBRE FESTAS PÚBLICAS NA CAPITANIA DE PERNAMBUCO
}

RESUMO: Este artigo se propõe a observar um tema caro à historiografia colonialista, a festa, a partir da análise crítica e paleográfica de três manuscritos. Partindo de sua transcrição, discutimos a produção desses documentos, sua inserção em um gênero textual específico - a correspondência administrativa - e seu conteúdo: os meandros das festas públicas na Capitania de Pernambuco entre o Seiscentos e o Setecentos. Considerandose tais festas como espaços privilegiados de demarcação de status e prestígio para a elite açucareira colonial, o artigo discute algumas possibilidades de estudo desse tema oferecidas pelos documentos camarários coloniais.

PALAVRAS-CHAVE: Documentação. Capitania de Pernambuco. Festas Coloniais.

ABSTRACT: This paper observes a prestigious thematic in Brazilian colonial historiography, the festivity, through the reading of three manuscripts. It analyses the paleographic elements of these documents, considering their textual gender - the administrative correspondence in the Portuguese Empire -, and the information

* Doutora em História pela Universidade Federal de Pernambuco (UFPE). Professora Associada da Universidade de Pernambuco (UPE), Professora do Mestrado Multidisciplinar em Hebiatria (UPE); e do Mestrado em História da Universidade Federal Rural de Pernambuco (UFRPE). Pesquisa financiada pelo CNPq. 
they provide in regard of the public celebrations in Seventeenth and Eighteenth centuries Pernambuco. The paper observes those celebrations as privileged spaces for status quo definition as well as the analytical possibilities offered by manuscript documentation.

KEYWORDS: Colonial Documentation. Pernambuco's Captaincy. Colonial Celebrations.

\section{Introdução - Para entender a produção dos manuscritos}

Durante os séculos XVII e XVIII, a Capitania de Pernambuco ocupou uma posição de prestígio dentro da América portuguesa, dominada por senhores de engenho e, a partir do XVIII, também por grandes comerciantes, assentados em câmaras municipais, dentre as quais se sobressaia a de Olinda. Tal situação privilegiada garantiu a essa elite uma atenção redobrada por parte da Coroa, materializada em uma intensa troca de correspondência administrativa entre o Conselho Ultramarino, governadores, ouvidores e outros funcionários régios, além dos próprios oficiais do Senado da Câmara de Olinda e de suas congêneres em Igarassu e, após 1711, em Recife. E é justamente essa correspondência administrativa que hoje possibilita aos historiadores acesso aos mecanismos políticos e socioculturais que nos Seiscentos e Setecentos interligavam essa capitania ao Império Português, na medida em que os agentes administrativos em diferentes lugares discutiam assuntos os mais diversos. Tal relevância historiográfica expõe a pertinência de uma análise crítica e paleográfica dessa prolífica documentação; uma análise, entretanto, que atualmente tem sido relegada a segundo plano por muitos historiadores sociais devido principalmente à constante utilização de acervos, como o Arquivo Histórico Ultramarino (AHU), cuja documentação já foi analisada a partir de diversos pontos de vista, inclusive o diplomático.

Contudo, muitos acervos coloniais brasileiros carecem de 
análises tão minuciosas. Apesar do imprescindível trabalho de preservação e divulgação que vem sendo realizado por grandes e pequenos arquivos brasileiros, na medida em que cresce a prospecção em "novos" acervos, os historiadores se veem constantemente confrontados com manuscritos que, diferentemente daqueles do $\mathrm{AHU}$, não são acompanhados de ementas que explicam sua autoria, detalhes de produção e elementos diplomáticos básicos. $\mathrm{E}$ esse confronto traz à luz $\mathrm{o}$ importante papel que a crítica documental pode desempenhar no trabalho historiográfico.

No caso específico da Capitania de Pernambuco, um acervo em particular ainda resguarda manuscritos que exigem detalhadas análises críticas antes de qualquer leitura conteudística. Esse acervo é o Fundo de Registros de Provisões, Portarias e Editais (1688 a 1905) do Arquivo Público Jordão Emerenciano, o APEJE, no Recife. Um fundo cuja recorrente leitura ao longo de anos nos despertou uma série de interrogações relativas ao processo de produção de seus manuscritos. E é para tentar responder a algumas dessas questões que nos propomos aqui a realizar uma leitura crítica, com considerações filológicas e paleográficas (QUEIROZ, 2011, p. 473-484), em três manuscritos pertencentes ao fundo em questão: três registros camarários que discutem um tema privilegiado pela historiografia especializada na América portuguesa - as festas públicas.

Em trabalhos anteriores, tivemos a oportunidade de visitar essa temática no cenário específico da Capitania de Pernambuco nos séculos XVII e XVIII (SILVA, 2011a, p. 63-85; SILVA, 2011b, p. 76-93; SILVA, 2009), o que gerou uma preocupação com a monumentalidade desses documentos, uma vez que, ausente qualquer análise diplomática ou crítica paleográfica, tais manuscritos estavam sendo aceitos como retratos indiscutíveis dos fatos e estruturas coloniais. Isso nos traz à leitura atual, através da qual procuramos não apenas inquirir sobre as intenções por trás da escrita dos três manuscritos selecionados, mas também contextualizar seu "lugar de produção", sendo esse lugar uma das mais importantes questões a serem discutidas aqui, visto que 
tais manuscritos possuem uma dupla datação, pois são cópias setecentistas de manuscritos seiscentistas. Nossos documentos se inserem naquela situação apontada por José D'Assunção Barros, na qual a cronologia da produção de um documento nem sempre se limita a um único "lugar": ou seja, uma situação presente quando o documento foi elaborado ou interferido ao longo de um dado intervalo de tempo (BARROS, 2012, p. 407429). Tal interferência é percebida na produção desses nossos manuscritos, o que levanta uma série de dúvidas acerca de seu valor enquanto monumento às estruturas e fatos coloniais.

\section{Quem escreve, quem copia - Sobre a autoria dos manuscritos coloniais do APEJE}

Hoje encadernados em um único volume, nossos três manuscritos são cópias de uma correspondência mais antiga, remetida pela Coroa portuguesa à Câmara de Olinda e procedente do Conselho Ultramarino que, desde sua fundação, em 1642, geria a maior parte dos negócios coloniais do Império português (SALGADO, 1985, p. 42-43). Eles pertencem a um gênero textual bem característico do mundo atlântico moderno e um dos mais prolíficos nos séculos XVII e XVIII: a correspondência administrativa imperial. O livro que os reúne, o Livro de registros, cartas, provisões e ordens régias da Câmara municipal da Cidade de Olinda de 1696, congrega, em suas 568 páginas manuscritas, as cópias, elaboradas na segunda metade do século XVIII, de ordens régias e de provisões enviadas à Câmara de Olinda, cujos originais datam do final do século XVII. Isso sugere que o escrivão em atividade nesse órgão na década de 1750 produziu uma "segunda via" de um livro de registro mais antigo, hoje perdido, que compilava a correspondência que a Câmara recebera da Coroa no século anterior. Por isso, na maioria de suas páginas vemos, abaixo dos dados relativos ao documento original seiscentista, também os dados do escrivão que o copiou nos anos 1750. Essa informação nos dá, na verdade, um autor autodeclarado para nossos três manuscritos: Manuel Pinheiro da Fontoura, escrivão da Câmara de Olinda em 1755. 
O Livro de registros... reúne provisões, ordens e cartas régias copiadas em sequência cronológica e em sucessão imediata, com o primeiro registro transcrevendo um documento cujo cabeçalho se perdeu, mas que ainda traz a data do original, 1663, e o último registrando uma provisão de 1709; apesar de que, em seu interior, ele também apresenta alguns registros datados da década de 1720. De forma geral, em bom estado de conservação, o livro está completo, a não ser por duas folhas que foram substituídas por cópias digitadas (LIVRO de registros, cartas, provisões e ordens régias da Câmara municipal da Cidade de Olinda de 1696, p. 71, 73), e traz manuscritos relativamente legíveis, apesar do óxido de ferro da tinta original estar corroendo letras em diversos lugares e começando a manchar muitas das páginas. As cópias ocupam as duas faces da folha, e os documentos têm tamanhos bastante desiguais, variando entre aqueles com menos de 20 linhas que ocupam meia página, dividindo-a com o documento seguinte, e aqueles que se espalham por várias páginas, caso do Registro do Regimento de Ordenanças expedido para esse governo, com 35 páginas (LIVRO de registros, cartas, provisões e ordens régias da Câmara municipal da Cidade de Olinda de 1696, p. 263-280). Por fim, ao final do tomo há um índice que ocupa as oito últimas páginas, intitulado Index das principaes ordens, e Cartas régias $q[e]$ contem este Livro; índice, entretanto, incompleto.

A análise paleográfica inicial desses manuscritos nos oferece elementos para uma descrição geral do contexto de sua produção. Em primeiro lugar, é perceptível que os registros não foram escritos por um único escriba, visto que o estilo de escrita muda consideravelmente ao longo das folhas. Por outro lado, apesar dos diferentes escrivães, os elementos paleográficos extrínsecos e intrínsecos (DURANTI, 2015, p. 196) mantêm todos os documentos dentro dos limites temporais estabelecidos por seu conteúdo, inserindo-os nos séculos XVII e XVIII: não apenas o material de suporte da escrita - por exemplo, a tinta manufaturada com óxido de ferro - mas também a escrita em si (que pode ser definida, de acordo com as regras paleográficas, como humanista com letras cursivas e encadeadas) são elementos 
bem característicos do período colonial (ANDRADE, 2008/2009, p 152). Todas essas considerações, é claro, excluem as duas páginas digitadas que foram visivelmente acrescentadas no final o século $X X$, mas que não trazem informações sobre sua data de produção ou de inclusão no livro.

Outros elementos significativos inserem o livro no contexto de produção dos documentos oficiais coloniais: o uso excessivo de abreviaturas (ACIOLI, 1994, p. 45-48); a ausência de clareza e padronização nos traços cursivos das letras em muitas das folhas (ANDRADE, 2008/2009, p. 158); a elaboração de vários de seus textos no formato de um parágrafo único; a elaboração dos textos segundo as convenções das cartas administrativas imperiais portuguesas, cuja formatação incluía cabeçalho, saudação, fecho, cargo do autor, local e data de produção, e assinatura do autor (FONSECA, 2006, p. 571). Da observação da conjunção desses elementos em manuscritos coloniais variados (principalmente 0 excesso de abreviaturas e as letras fora de padrão), autores como Andrade e Acioli deduzem um domínio irregular das técnicas de escrita por parte dos escrivães responsáveis (ACIOLI, 1994, p. 45-48; ANDRADE, 2008/2009, p. 158). No entanto, não podemos precisar se esse era o caso de Manuel Pinheiro da Fontoura, o escrivão-autor dos três documentos aqui analisados, uma vez que muito ainda há a ser estudado no que diz respeito à cultura escrita no contexto específico da Capitania de Pernambuco e pouca ou nenhuma informação biográfica foi até agora encontrada sobre esse personagem.

Seja como for, a partir dessas considerações gerais, procedemos à transcrição paleográfica e leitura crítica de nossos três manuscritos, baseando-nos principalmente nas regras ditadas por Acioli (1994), mas considerando também as reflexões filológicas acerca da edição semidiplomática de documentos manuscritos, como propostas por Vasconcelos (2005) e Barreto e Queiróz (2011). Como consideração inicial, ressaltamos que a autoria desses três registros selecionados vem declarada nos mesmos: o escrivão Manuel Pinheiro da Fontoura. Além disso, os três documentos compartilham a maioria dos elementos 
paleográficos extrínsecos e intrínsecos com a notável exceção da clareza na grafia, já que o segundo e o terceiro documentos apresentam uma escrita muito mais homogênea, com letras mais regulares do que o primeiro, e mesmo com um menor número de abreviaturas. Também é significativo que apenas o registro da provisão de 1726 faça referência clara ao Conselho Ultramarino.

Sobre o que se escreve - 0 conteúdo dos manuscritos do Livro de registros, cartas, provisões e ordens régias da Câmara Municipal da Cidade de Olinda de 1696

No que se refere ao conteúdo, os documentos do Livro de registros, cartas, provisões e ordens régias da Câmara municipal da Cidade de Olinda de 1696 tratam de assuntos os mais diversos, principalmente discutindo o cotidiano da Câmara de Olinda e sua relação com a Coroa em um momento em que a dita câmara comandava a Capitania de Pernambuco. Razão pela qual o livro compila resoluções sobre despesas diversas, sobre abastecimento local, sobre nomeações para cargos públicos e militares, além de discutir outras funções regulares da câmara, como a organização das festas públicas. ${ }^{1} \mathrm{E}$ foi a relevância política e social dessas festas no contexto das disputas entre diferentes grupos sociais em Pernambuco, entre o XVII e o XVIII, que nos levou a explorar os conteúdos e os discursos dos manuscritos desse livro em primeiro lugar, despertando diversas questões sobre a autoria e o lugar de produção de documentos, como os três que analisamos aqui: duas provisões e uma carta régia que versam sobre as festas públicas sob responsabilidade da Câmara de Olinda nas décadas de 1690 e 1720, cujos registros foram copiados no Livro de registros... por Pinheiro da Fontoura em 1755.

O primeiro dos nossos três manuscritos é o Registro da carta de Sua Majestade, escrita à Câmara, sobre o Governador não consentir que diante dele se assentarem cadeiras de espaldas.

1 Para as funções administrativas da Câmara de Olinda, cf. Lisboa, 2013. 
Escrita a 13 de novembro de 1691. As datas de cópia e original estão estabelecidas no próprio documento, respectivamente 1755 e 1691. Quanto à tipologia, é uma carta régia que responde a uma correspondência anterior da Câmara de Olinda, cuja data não é mencionada. E, quanto ao assunto, responde a uma queixa dos oficiais dessa câmara relativa a determinada atitude do governador de Pernambuco durante uma celebração pública. O manuscrito está na página 63 verso do Livro de registros..., dividindo-a com um segundo documento copiado na mesma data, intitulado Registro da carta de sua majestade, escrita aos oficiais da câmara na q[a] Ihe dis mandar ordenar ao governador senão intrometer nas eleições e os deixe servir q[to] le os tocar. Escrita a 6 de dezembro de 1691, e os títulos de ambos já esclarecem sua função enquanto cópias de uma documentação mais antiga. Segue abaixo sua transcrição, com a grafia atualizada para o português atual:

Registro da carta de Sua Majestade, escrita à Câmara, sobre o Governador não consentir que diante dele se assentarem cadeiras de espaldas. Escrita a 13 de novembro de 1691.

Oficiais da Câmara da Cidade de Olinda Eu El Rey vos envio muito saudar, vendo o que me escreveste em carta de 10 de julho do ano passado, sobre o governador Antônio Luiz Gonçalves da Câmara Coutinho, vos não querer no tempo de seu governo consentir que nos atos públicos em sua presença vos assentásseis em cadeiras de espaldas senão em bancos os tendo [naposse] de vos assentardes em cadeiras de espaldas em todas as ocasiões, que em atos públicos e em festas reais, assistires em corpo de câmara, em presença dos governadores, e só estando o Santíssimo exposto, em bancos; e vendo também o que sobre esta matéria informou (como Ihe mandei ordenar), o Governador Antônio Felix Machado, em carta de 12 de julho deste ano: me pareceu ordenar vos, que ao mesmo governador se os observe que vos consinta naposa [sic] de vos sentardes nos atos públicos, em cadeiras de espaldas, de que vos aviso, para o terdes assim entendido: Escrita em Lisboa a 
13 de novembro de $1691=$ Rei $=$ o Conde de Valadares $=$ para os oficiais da câmara de Pernambuco: era o que se continha na dita carta, que eu Manuel Pinheiro da Fontoura, escrivão da câmara, a fiz registrar, subscrevi, e assinei aos 32[sic] de janeiro de 1755 Manuel Pinheiro da Fontoura. (LIVRO de registros, cartas, provisões e ordens régias da Câmara municipal da Cidade de Olinda de 1696. fl. 63v).

Nesse texto, o Conselho Ultramarino basicamente informa à Câmara de Olinda qual a decisão régia tomada com referência a uma reclamação anteriormente feita por aquele órgão. Apesar de ser um texto curto e sucinto, deixa transparecer, entre outras coisas, o processo administrativo por trás da recepção da queixa e da subsequente tomada de decisão sobre a mesma. Indica, por exemplo, a investigação feita junto aos representantes da Coroa em Pernambuco, motivada pela recepção da correspondência que primeiro relatou o episódio em discussão. Uma investigação que implicava o envio de missivas consultivas para representantes como o governador da capitania, Antônio Felix Machado. Recebendo o parecer deste, o Conselho Ultramarino, através do Conde de Valadares, decidiria sobre o problema e informaria a decisão ao rei que, por fim, mandaria passar a ordem explicita nessa carta régia.

Também a duração da investigação aparece na mensagem, que fixa o tempo decorrido entre o recebimento da primeira queixa e o envio da decisão régia sobre a mesma: a primeira correspondência sobre o assunto, tendo sido recebida na Corte em julho de 1690, e a ordem passada pelo rei, escrita em novembro de 1691. Por fim, o documento é concluído com o registro da assinatura do rei e do membro do Conselho Ultramarino originalmente responsável por encaminhar a carta, nesse caso o Conde de Valadares, e pelos dados do copista de 1755, o escrivão Manuel Pinheiro da Fontoura.

Com relação ao assunto tratado pela carta régia de 1691 , a mesma aborda um tema caro à cultura cortesã ibérica, e, por extensão, à sociedade colonial americana: a geografia de poder 
nas cerimônias públicas. ${ }^{2}$ Nesse caso específico, a problemática discutida girava em torno da disputa entre os oficiais do Senado da Câmara de Olinda e o governador da capitania, então Câmara Coutinho, acerca do tipo de assento que os oficiais poderiam ocupar nas cerimônias públicas realizadas nas vilas da capitania: enquanto os oficiais queriam sentar em cadeiras de espaldas nas cerimônias mais importantes, aquelas com o Santíssimo Sacramento exposto, o governador os obrigava a permanecer em bancos simples.

A simplicidade, ou superficialidade, dessa discussão disfarça profundas disputas políticas entre os senhores de engenho e os representantes da Coroa portuguesa em Pernambuco, ecoando uma queixa nada original, e mesmo bastante repetida ao longo dos séculos XVII e XVIII. Isso porque na medida em que os festejos públicos se configuravam como momentos privilegiados para que os senhores, enquanto membros das câmaras, demarcassem seu prestígio, as disputas pelos melhores posicionamentos nas cerimônias se tornavam cada vez mais comuns (SILVA, 2009). Essas celebrações, que incluíam festas religiosas anuais pertencentes ao calendário da Coroa e posses de autoridades e festas extraordinárias de cunho político - casamentos, nascimentos, exéquias - ordenadas pela Corte, apresentavamse como os momentos principais de exposição dos senhores de engenho nas ruas das vilas da capitania. Logo, todas as festividades processionais eram rigorosamente planejadas e implicavam uma hierárquica distribuição de espaços que tornava a geografia das cerimônias um assunto dos mais importantes para esses senhores.

2 Trabalhamos com a noção de cultura cortesã como aquele sistema de valores, em vigor entre a nobreza residente e atuante nas cortes da Europa seiscentista, cujas complexas regras de conduta, segundo José António Maravall, atingiram seu ápice na Espanha Habsburga, e que de lá se espalharam para reinos e colônias conectados ou pertencentes ao domínio Habsburgo. Para a cultura cortesã, cf. Maravall, 1997; Bennassar, 2006; Oliveira, 2006. Em trabalhos anteriores, aprofundamos a relação dos senhores de engenho da América portuguesa com essa cultura. Cf. Silva, 2013. 
Como na hierarquia espacial dessas procissões, determinados símbolos ocupavam posições mais destacadas, caso principalmente do Santíssimo Sacramento, que era apresentado apenas nas mais importantes celebrações. A presença eventual desses símbolos acendia as disputas por espaços privilegiados entre oficiais das câmaras, governadores, bispos e todas as outras autoridades da capitania (SILVA, 2011b, p. 76-93).

$\mathrm{E}$, de fato, a carta régia de 1691 implicava que a presença do Santíssimo Sacramento na cerimônia em questão fora o estopim do problema entre Câmara e governador acerca do lugar onde os oficiais da primeira deveriam se sentar na festa. $O$ fato de 0 governador os ter obrigado a sentar em bancos simples, em uma ocasião tão importante que exigia a exposição do Santíssimo, levou esses indignados senhores de engenho, enquanto oficiais camarários, a repassarem seu desgosto para o rei.

Essa não foi a primeira e tampouco a última vez em que problemas políticos foram gerados na Capitania de Pernambuco em torno da realização de festas públicas. Em primeiro lugar, é preciso considerar a função básica dessas cerimônias: reafirmar o poder do rei sobre os distantes súditos coloniais. Uma função jamais esquecida e sempre enfatizada: em diferentes ocasiões vemos governadores e câmara disputando o privilégio de representarem o rei.3 Por outro lado, para além dessa função, a própria condição colonial de existência criou uma outra igualmente importante para os oficiais da câmara: aquela que dava às festas o poder de definir publicamente hierarquias estamentais, confirmando o prestígio de autoridades perante a capitania e mesmo a Coroa.

Assim, cada festa pública tinha sua geografia estabelecida minuciosamente, e os espaços nas procissões, nos sermões e cerimônias, nas igrejas e nas danças das corporações eram

3 Cf. REGISTRO da carta de S. majestade escrita aos oficiais da câmara, sobre ir, ou não o pendão da câmara nas procissões. Escrita a 18 de julho de 1677. APEJE. LIVRO de registros, cartas, provisões e ordens régias da Câmara municipal da Cidade de Olinda de 1696. FI. 48, 48v. 
cuidadosamente arranjados de forma a que indicassem aos espectadores o status de seu ocupante. ${ }^{4}$ Nesse contexto, os símbolos dessas cerimônias eram vitais, pois o prestígio poderia ser estabelecido pelo lugar ocupado por um personagem em relação a um desses símbolos: o pálio e o Santíssimo Sacramento são os melhores exemplos (SILVA, 2009). Não que essa tão bem arranjada distribuição espacial impedisse o surgimento de problemas. Pelo contrário: as disputas surgiam e se tornavam mais acaloradas quanto mais importante era a cerimônia em questão.

No caso específico da disputa apresentada pela carta de 1691, a Coroa terminou por dar razão à Câmara de Olinda em detrimento do governador, resguardando assim o prestígio dos senhores de engenho. Isso também não era raro, e, em outras querelas suntuárias entre câmaras e governadores, a Coroa afirmaria que também os oficiais dos senados eram seus representantes, e por isso deveriam ser tratados com o devido respeito e associados aos símbolos de poder público. ${ }^{5}$ Por outro

4 Para a análise das festas públicas na Capitania de Pernambuco, enquanto eventos privilegiados para a observação da cultura política dos senhores de engenho, trabalhamos com a sociologia weberiana e seus conceitos elaborados para análise de grupos de status: conceitos tais como prestigio, honra e status, esse último compreendido como o lugar simbólico ocupado pelos senhores de engenho na estrutura hierárquica da capitania. O que essa concepção teórica traz para a análise histórica da cultura política desses senhores é a constatação do quanto, para aqueles indivíduos que compunham o grupo de status dos senhores de engenho da capitania, a manutenção da honra e o cultivo de prestígio eram fundamentais ferramentas de aquisição de poder (WEBER, 2002, p. 687-688; QUINTANEIRO, 2002, p.114-119).

Um exemplo é a disputa entre o Vigário Geral da Sé de Olinda e a Câmara desta cidade, em 1677, em torno do lugar que o pendão da Câmara deveria ocupar nas procissões, em relação à posição do pálio. Nessa disputa, interveio o então governador de Pernambuco, D. Pedro de Almeida, posicionando-se contra o Senado. O que levou a Câmara a escrever ao rei uma reclamação contra vigário e governador. O rei, por sua vez, nessa ocasião como em outras, posicionou-se a favor da Câmara, afirmando: "que o governador não representa mais minha pessoa do que a representa o senado: e assim não havia de resolver que nas procissões que não fosse o pendão porque só quando eu vou nelas deixa de ir, o pendão e nas mais começa do pendão 
lado, no que diz respeito à distância temporal entre a carta original e a cópia setecentista, é preciso ainda observar que tal distância, com relação a esse tema específico, talvez não existisse. De fato, as disputas por prestígio na Capitania de Pernambuco ainda eram bastante comuns na segunda metade do século XVIII, tendo até mesmo sofrido uma intensificação com a concorrência oferecida pela fundação da Vila do Recife, em 1711. Isso fazia com que os assuntos tratados na carta original fossem bastante atuais no momento de sua cópia, fazendo sentido, assim, que, em 1755, a Câmara se interessasse por registrar um documento antigo que resguardasse seus direitos em querelas futuras.

Visto que as festas públicas ocupavam um papel dos mais importantes nas vilas coloniais, funcionando como vitrines para o rei distante e para as elites locais ${ }^{6}$, não é de se espantar que ocupassem também as preocupações das câmaras, que gastavam muito tempo discutido cotidianamente diversas questões

o corpo do senado da câmara, e nesta forma se deve observar daqui em diante". (REGISTRO da carta de S. majestade escrita aos oficiais da câmara, sobre ir, ou não o pendão da câmara nas procissões. Escrita a 18 de julho de 1677. APEJE. LIVRO de registros, cartas, provisões e ordens régias da Câmara municipal da Cidade de Olinda de 1696. 48, 48v).

6 Atualmente, são numerosos os estudos que se debruçam sobre as elites coloniais e sua relação com as câmaras municipais da América portuguesa. Essa historiografia tem se esforçado para definir a noção de elite colonial - que normalmente abarca os grupos que controlavam tanto os meios econômicos quanto os poderes políticos locais em suas regiões específicas -, assim como para entender a balança de poder entre esses poderes locais e aqueles das autoridades coloniais e do próprio Estado português (NOGUEIRA, 2010.). Essa historiografia é numerosa e abarca diferentes recantos da América portuguesa, mas, em geral, segue consideravelmente influenciada pelas teses primeiramente expostas no hoje clássico O Antigo Regime nos trópicos (FRAGOSO; BICALHO; GOUVÊA, 2001). Para Pernambuco, especificamente, a definição das elites camarárias foi feita por historiadores como George Cabral, para quem as câmaras eram instituições hibridas de poder (SOUZA, 2007). Seguindo a mesma linha, Welber Carlos Andrade a Silva discute a maleabilidade das elites coloniais, mas enfatizando a importância da posse fundiária na definição dessas na Capitania de Pernambuco, pelo menos até o XVIII, quando o comércio se tornou um fator também definidor da composição dessas elites na capitania (SILVA, 2012, p. 26). 
relacionadas a esses eventos, como as despesas envolvidas em sua organização. Essas despesas eram sempre vultosas e incluíam pagamentos de pintores e músicos, de sermões especialmente encomendados, de cera para a iluminação pública, além das propinas para os próprios oficiais do senado. ${ }^{7}$ Esse tópico do financiamento das festas foi uma constante também em Pernambuco, e é o tema de nosso segundo manuscrito: o registro de uma provisão régia, originalmente datada de 1692.

Registro de uma provisão por que Sua Majestade manda se tirem os $6^{40}$, que a cada um dos juízes, vereadores da câmara de Pernambuco se dá para varas, porém, que estas tenha o Senado obrigação de lhas dar por sua conta passada a 19 de setembro de 1692.

Eu El Rei, faço saber aos que esta minha provisão virem, que mandando ver e examinar as dúvidas que o ouvidor geral da Capitania de Pernambuco, José de Sá Mendonça, teve para não levar em conta nas que viu e reenviou, por ordem do governador D Antonio Felix Machado do tesoureiro do Senado da Câmara Feliciano da Silva, algumas despesas, que os oficiais da dita câmara costumam fazer sem provisão minha, e o que sobre esta matéria me responderam os mesmos oficiais da câmara, governador, e sindicante da dita capitania de Pernambuco, tendo a tudo consideração e ao que respondeu o procurador da minha fazenda ao que se deu vista: haja bem que se tirem os seis contos,

7 Camila Santiago compôs uma ótima reconstituição de todo o processo de organização das festas públicas pelas câmaras, "desde a decisão por fazêlas, acordada em reunião do conselho, passando pela contratação de oficiais e sacerdotes - músicos, carpinteiros, padres, armadores - o gerenciamento das contas públicas destinadas às celebrações, a convocação dos segmentos sociais para tomarem seus lugares nas solenidades, a compra de materiais necessários como cera e incenso etc.". Seu objeto de estudo foram as festas organizadas pela Câmara de Vila Rica, no XVIII, mas seu trabalho nos oferece um bom parâmetro do funcionamento das mesmas nos núcleos urbanos ultramarinos. Cf. Santiago, 2001, p. 13. 
e quarenta réis, que a cada um dos juízes e vereadores da dita câmara se dá em cada uma das festas para varas, porem que estas terá o dito senado da câmara a obrigação de lhas dar por sua conta, e despesa; e nesta conformidade mando se cumpra, e guarde esta provisão inteiramente, como nela se contem, sem dúvida alguma, a qual se lerá como carta, e não passará pela chancelaria, sem embargo da ordenação do [Artigo $]\left[2^{\circ}\right]\left[{ }^{\left.11^{\circ}\right]} 39\right.$ em contrário, e se passou por [ ] Manuel Felipe da S[a], a fez em Lisboa, a 19 de junho de 1692, o secretário.

O secretário André Lopes de Serra a fez escrever, Provisão por que $\mathrm{V}$. Majestade manda que se tirem os seiscentos e quarenta réis que cada um dos juízes e vereadores da Câmara de Pernambuco se dá em cada uma das festas por varas, porem que estas tenha o dito Senado da Câmara a obrigação de Ihas dar por sua conta e despesas, como nesta se declara e não passa pela chancelaria, haveis por dever para V. Maj. ver = é o que se conta na dita Carta que eu Manuel Pinheiro da Fontoura, escrivão da Câmara o fiz registrar, subscrevi e assinei em 8 de fevereiro de 1755. Manuel Pinheiro da Fontoura. (LIVRO de registros, cartas, provisões e ordens régias da Câmara municipal da Cidade de Olinda de 1696. fl. 66).

Diferentemente de uma carta régia, dirigida pela Coroa a um interlocutor específico sobre um tema em particular, uma provisão era uma ordem de caráter mais geral; uma diferença que pode ser percebida na comparação dos dois documentos anteriores, pois enquanto a carta régia de 1691 foi dirigida especificamente aos oficiais da Câmara de Olinda, resguardando um certo tom de consulta, a provisão de 1692, por sua vez, não apenas foi dirigida a todos os representantes régios da capitania, como também apresentava um tom claro de ordem. Nela, a diretriz real impunha uma mudança nas práticas da Câmara de Olinda, em resposta a um problema anteriormente identificado nas contas da mesma.

A situação que motivou essa ordem aparece na provisão de forma sintética: aparentemente seguindo ordens do governador 
da capitania, então Felix Machado, o ouvidor geral da capitania - funcionário encarregado da manutenção da Justiça Régia - levantou dúvidas sobre a idoneidade das contas prestadas pelo Tesoureiro da Câmara de Olinda, especificamente aquelas relativas às despesas que, sem permissão régia, os oficiais faziam nas festas. Uma vez tendo recebido essas dúvidas, a Coroa ordenou uma sindicância, que foi realizada pelo procurador da fazenda, que, por sua vez, apresentou seus resultados ao Conselho Ultramarino; a partir desses resultados, foi elaborada a provisão em questão.

Os gastos disputados nessa ocasião em particular eram relativos ao pagamento de varas aos oficiais do Senado. Mais especificamente ainda, ao pagamento de seis contos e quarenta reis, um valor bem alto para a década de 1690, em varas para cada uma das festas organizadas por aquela câmara no ano em questão. E essas festas foram muitas...

Como prática costumeira no Império português, cabia às câmaras das vilas mais influentes a organização das festas anuais do calendário régio, ditado na Corte. Tais festas, das quais Corpus Christi era a mais importante, eram celebrações religiosas com um forte caráter de reafirmação do poder da monarquia e que tomavam a forma de atos processionais, seguidos ou precedidos de cerimônias nas igrejas, muitas vezes acompanhados pelos terços do exército regular, e sempre guiados pelas autoridades locais.

Essas festas custavam caro, pois exigiam, entre outras coisas, a iluminação das ruas e igrejas, a contratação de músicos e de padres pregadores, tudo devendo ser financiado pelas câmaras, que também deveriam pagar as propinas e varas devidas aos oficiais do senado por sua participação. Enquanto as propinas eram pagamentos comuns a funcionários do império, as varas, por sua vez, eram importantes símbolos associados às celebrações públicas, no mesmo patamar do pendão da câmara. Eram insígnias associadas às irmandades leigas, que deveriam ser carregadas por seus mais importantes irmãos nas procissões 
de seus santos padroeiros.8 E, a julgar pela provisão de 1692, eram associadas também ao pagamento de um valor determinado que deveria ser feito pela câmara a seus portadores.

Na década de 1690, as principais festas do calendário régio organizadas pela Câmara de Olinda eram as anuais Corpus Christi, São Sebastião, Anjo Custódio do Reino e a festa de Ação de Graças pela Restauração da Capitania contra os Holandeses, às quais se somavam as eventuais festas extraordinárias, tais como a realizada em honra do nascimento da infanta em 1699 e as celebrações da "paz com Castela", que renderia festas ainda em 1713, 1715 e 1719. Interessante notar que, apesar do calendário festivo ser o mesmo para reino e ultramar, a Câmara de Olinda conseguiu que o rei transformasse uma celebração local em festa anual, realizada apenas na vila: a festa de ação de graças pela Restauração (SILVA, 2009). Além dela, o governador de Pernambuco, então Aires de Souza, fez celebrar, nessa mesma década, também festas extraordinárias de caráter local, em honra à pretensa conquista do Quilombo de Palmares. ${ }^{9}$

Seja como for, a operação dessas festividades seguia sempre um padrão pré-determinado, com procissões guiadas por ruas selecionadas e devidamente enfeitadas para a ocasião, com luminárias, repiques de sinos, salvas de artilharia, pregões públicos e às vezes danças das corporações de ofício, e cuja conclusão deveria se dar na Igreja Matriz, com missa solene na qual era cantado o Te Deum e onde se expunha o Santíssimo Sacramento naquelas festas mais prestigiosas, que eram acompanhadas por tropas e assistidas pela plebe. Em tudo isso, a participação das autoridades era devidamente organizada segundo a rígida hierarquia espacial das festas coloniais (SILVA, 2011a, p. 63-85).

No caso que motivou a escrita dessa nossa provisão de 1692 ,

8 Para o pagamento de propinas e os significados das varas nas procissões (SANTIAGO, 2001, p. 11; 19; 70; 96).

9 Dados acerca dessas festas estão nos documentos transcritos por Ennes (1938, p. 31-32; 105-106). 
as despesas que o ouvidor deixou sob suspeita contabilizavam um gasto considerável que tinha saído dos cofres da Fazenda Real. Aparentemente, o problema não era o pagamento das varas em si, uma prática costumeira, mas o fato de que o mesmo estava sendo realizado pelos fundos da Fazenda Real e não pela câmara, como deveria ser o procedimento correto. Não que isso fosse um fenômeno raro, sendo, na verdade, bastante comum que as câmaras municipais luso-americanas abusassem de seu papel de organizadoras das festas públicas e de seu direito legal de receber pagamento pela participação nas mesmas, estipulando altas somas para suas propinas.

Mas, além desse problema financeiro, esse curto manuscrito é esclarecedor também de uma outra questão corriqueira naquele cenário: a constante disputa de poder entre a Câmara de Olinda e as autoridades régias na Capitania de Pernambuco. Assentados nessa câmara estavam os senhores de engenho: um grupo que, pelo menos desde a restauração em 1654, se arrogava privilégios de mando sobre a capitania e mesmo além dela, e que não poucas vezes se enfrentava aos altos representantes do rei, especialmente os governadores que deveriam ser responsáveis pela imposição da ordem imperial na região.

Há o caso, por exemplo, de uma disputa entre essa câmara e o governador D. Manoel Rolim de Moura, em 1725, acerca da obrigatoriedade, não cumprida, de o governador atender às festas em Olinda (CARTA do governador da Capitania de Pernambuco ao Rei sobre a ordem para que todos os ministros, oficiais de justiça e fazenda, governador, Senado e todos os terços de Recife e Olinda participem dos festejos da Restauração... Pernambuco, 18 de julho de 1725). Nessa ocasião, reclamaram os oficiais de Olinda que o governador não apenas não comparecera à festa de ação de graças pela Restauração naquele ano, mas ainda impedira que as tropas e outras autoridades da Coroa então assentadas no Recife participassem da festa em Olinda, o que, segundo os oficiais, diminuíra consideravelmente a pompa da ocasião. Ou seja, tratava-se de uma disputa por pompa e por autoridade. Uma disputa que também transparece na investigação das contas da 
câmara instigada pelo governador Felix Machado no episódio retratado pela provisão de 1692 copiada em nosso manuscrito. $E$ uma disputa, além disso, que ainda se fazia sentir na década de 1750, quando esse registro foi elaborado. Em 1740, por exemplo, a disputa pelas festas públicas em Pernambuco se estendera a ponto de incluir também a Câmara de Igarassu (CARTA dos oficiais da câmara de Igarassú ao rei, d. João V, pedindo ordem para fazer ação de graças pela Restauração da capitania de Pernambuco do poder dos holandeses, como se faz anualmente em Olinda, no dia 27 de janeiro...).

Todas essas querelas eram disputas por prestígio e, logo, por poder. Mas é preciso ainda enfatizar que, como sugere a provisão de 1692 ao discutir o problema do pagamento das varas, a questão monetária era também um fator relevante.

Por fim, nosso terceiro documento, que copia um original de 1724, fala de um cenário político bem diferenciado daquele da Capitania de Pernambuco na década de 1690. Apesar de que, em termos da produção do manuscrito, o padrão já discutido se mantenha: o tom de ordem condizente com o de uma provisão se faz sentir e sua autoria é declarada, atribuída a Pinheiro da Fontoura em 1755.

Registro da provisão em que Vossa Majestade não foi servido deferir o requerimento feito por este Senado sobre a procissão que queriam fazer dia da visão de Nossa Senhora.

Dom João por graça de Deus rei de Portugal e dos Algarves, daquém e dalém mar em África, senhor da Guiné etc. Faço saber aos oficiais da Câmara da Cidade de Olinda, que se viu o que me representastes em carta de 9 de março do ano de 1724 de que entre as mais obrigações, que vos incumbia, é a de fazerdem [sic] uma solene procissão no dia da visão de Nossa Senhora, e outra no dia do Anjo Custódio, o que não haveis praticado por vossos antecessores, e porque não havia ordem em contrário, vos constava que nas vilas de Igarassú e Itamaracá se faziam estas solenidades ficáveis deliberados a pô-las em praxe, e por me ser presente por 
informação que neste particular mandei tomar que nestas vilas, que referis, se não fazem as tais procissões, e as festas constam de um sermão, e missa cantada. Me pareceu dizer-vos, observeis neste particular o estilo: El Rey Nosso Senhor o mandou por Antonio Roiz [Rodrigues] da Costa, e o Doutor José Gomes de Azevedo, conselheiros do seu Conselho Ultramarino, e se passou por 2 vias: Dionísio Cardoso Pereira as fez em Lisboa Ocidental, a 21 de maio, de 1726 = o secretário Andre Lopes da Lavra a fez escrever $=$ Antonio Roiz da Costa $=$ José Gomes de Azevedo $=$ Era o que se continha na dita Provisão que eu Manuel Pinheiro da Fontoura, escrivão da câmara, fiz registrar, subscrevi e assinei aos 7 de agosto de 1755. Manuel Pinheiro da Fontoura. (LIVRO de registros, cartas, provisões e ordens régias da Câmara municipal da Cidade de Olinda de 1696. FI, 153).

A mudança está no contexto social e político do documento original, principalmente porque Olinda deixara de ser vila, passando a cidade em 1696, e, mais importante, deixara também de abrigar a única câmara com poder de mando na região, desde que o Recife se transformara em vila em 1711. Além disso, naquele momento, a cidade precisava lidar também com o peso de outras vilas, como Igarassu e Itamaracá.

Essa mudança política se faz sentir no conteúdo do documento, que apresenta basicamente uma reprimenda do rei relativa à realização de duas festas públicas, a procissão de Nossa Senhora e a festa do Anjo Custódio, pela Câmara de Olinda. A Coroa reprime os oficias da câmara não apenas pela realização dessas procissões, mas pela informação incorreta que haviam dado como justificativa para as festas em Olinda: a de que as mesmas estavam sendo realizadas pelas câmaras de Igarassu e Itamaracá. O rei não apenas desmente essa informação, como ressalta o fato de que era obrigação de Olinda seguir a tradição e se ater a seus deveres específicos.

Duas questões se tornam imediatamente notáveis nessa discussão, principalmente quando comparadas a dos documentos anteriores: em primeiro lugar, o esforço da Câmara de Olinda por 
realizar festas que não eram mais reconhecidas como de sua alçada; e, em segundo, a posição da Coroa contrária à câmara.

No caso da primeira questão, a insistência dos oficiais do senado olindense em organizarem duas festas que em períodos anteriores eram exclusividade de sua cidade é um forte indício da mudança de status de sua câmara. Os oficiais queriam realizar procissões, com todas as pompas inclusas - como as que eram realizadas na década de 1690 -, e a Coroa insistia que eles se restringissem à fórmula simples de sermão e missa cantada para comemorar as ocasiões em questão. Interessante também que os oficiais do Conselho Ultramarino tenham enfatizado a necessidade de que aqueles da Câmara de Olinda preservassem o "estilo", ou seja, a tradição do modelo de realização das festas, ignorando totalmente o fato de que menos de cinquenta anos antes o modelo era o de festas estendidas com procissões. $E$ a segunda questão de nota é o fato de que, diferentemente de várias situações anteriores, relativas às querelas provocadas por Olinda em torno das festas, nessa ocasião específica, a Coroa se posicionou contra a câmara. Tudo isso sugerindo a decadência política de Olinda no período.

Por outro lado, é importante também ressaltar que, nesse mesmo momento, a Câmara de Olinda estava envolvida em uma disputa com a Câmara do Recife pela realização da festa de Corpus Christi. Provocada pela intenção da nova Câmara do Recife organizar sua própria festa de Corpus Christi, a mais importante do império, essa disputa se estendeu por décadas (SILVA, 2011b), uma vez que Olinda tudo fez para impedir que tal intenção se concretizasse. Esse esforço do Senado de Olinda por manter o monopólio sobre Corpus Christi e a relutância da Coroa em lhe apoiar apena reforçam a dificuldade que essa câmara estava encontrando, na década de 1720, para conseguir permissão para realizar outras festas que classicamente sempre estiveram em sua esfera de jurisdição, como a do Anjo Custódio do reino, descrita na correspondência da década de 1690 como uma das quatro mais importantes do calendário festivo régio. $\mathrm{E}$ as autoridades do Conselho Ultramarino se posicionavam 
favoráveis ao Recife na disputa por Corpus Christi. Uma situação que reforçava tanto a decadência política da Câmara de Olinda quanto a ascensão da do Recife.

Para além da mudança de cenário político dos senhores de engenho de Olinda, essa provisão de 1726 também oferece pistas para outras questões relativas à organização das festas públicas, como, por exemplo, os próprios elementos que compunham uma celebração régia. Nesse texto, vemos menção a missas cantadas com sermão nas festas realizadas em Igarassu e Itamaracá e ao fato de que a Câmara de Olinda não considerava que essas missas fossem suficientes para uma festa importante, reclamando da ausência de procissões. A queixa da Coroa era sobre o fato de que Olinda fizera a festa com procissão, um tipo de evento reservado para as mais importantes celebrações cortesãs (FURTADO, 1997). E o fato de que a Coroa negava tal ferramenta de prestígio à Câmara de Olinda é bastante indicativo da queda dessa câmara das graças da Corte.

Já em consideração ao processo de produção do registro dessa provisão pelo escrivão Manuel Pinheiro da Fontoura, diferentemente de nossos dois primeiros documentos, a distância temporal entre a elaboração da cópia e a provisão original é muito menor. E não apenas a distância temporal, mas o próprio contexto político era muito semelhante entre a década de 1720 e a de 1750, com a crescente decadência das câmaras que antes haviam sido bastiões dos senhores de engenho, como Olinda e Igarassu, e a gradual ascensão da Câmara do Recife. Contudo, se esses contextos sociopolíticos dessa cópia/original em particular são análogos, o que dizer dos diferentes lugares de produção dos dois documentos anteriores?

De forma geral, as cópias setecentistas observadas aqui são representações de uma ponte entre o contexto político de 1690 e o de 1750 , visto que registram documentos seiscentistas que discutiam questões ainda relevantes para o órgão que as elaborou na segunda metade do século XVIII. Esses manuscritos são, assim, fontes para os dois contextos, o da produção do original e o da produção da cópia? Ou apenas para um ou outro desses momentos? 
Seja como for, de certo temos apenas o fato de que o duplo lugar de produção desses manuscritos não deve ser ignorado pelos historiadores que se debruçam sobre eles em busca de informações sobre as câmaras pernambucanas coloniais, sobre festas, sobre abastecimento, sobre elites, sobre querelas governamentais ou outro qualquer assunto. Acreditamos que, ao reconhecermos o duplo lugar de produção dos manuscritos do Livro de registros, cartas, provisões e ordens régias da Câmara municipal da Cidade de Olinda de 1696 do APEJE, estamos facilitando o processo de leitura e análise dessas fontes. E, de forma geral, cremos que a análise particularizada dessa coleção de documentos aqui selecionada pode ser entendida como um exemplo dos benefícios da revisão, revitalização e reutilização das ferramentas filológicas e paleográficas no manejo de fontes manuscritas coloniais.

Isto é, a crítica documental básica, que observa e analisa tanto os elementos diplomáticos extrínsecos quanto os intrínsecos, ainda pode ser uma ferramenta válida para o estudo da correspondência administrativa colonial arquivada em acervos tais como o APEJE, principalmente por enfatizar a percepção de que, em tais acervos, o historiador está tratando com cópias elaboradas por câmaras locais, e não com a correspondência régia original. Ela também enfatiza o fato de que não temos o outro lado da conversa, as cartas escritas pelos órgãos coloniais e que motivaram tais respostas régias; assim como o fato de que estamos lidando com cópias produzidas por um escrivão e agregadas em um único livro, ou seja, com uma seleção feita por um burocrata setecentista e não com a coleção completa de cartas originais; e, por fim, com elementos, esses e outros, que podem dizer respeito mais ao lugar de produção da cópia do que do original.

Todos esses elementos trazidos pela crítica documental sugerem que a reflexão sobre a produção de fontes como esses registros manuscritos de documentos coloniais pode ser uma ação tão importante no trabalho com fontes oficiais coloniais quanto as análises de conteúdo e de discursos. Assim, os historiadores que 
optarem pelo emprego de ferramentas filológicas e paleográficas na abordagem de suas fontes podem começar por acrescentar àquelas perguntas iniciais feitas ao documento (quem escreve, para quem escreve, de onde escreve), outras definidas pelo formato desses manuscritos específicos: quem copia, quando copia, para que copia. Dessa forma, a leitura que oferecemos dos três manuscritos aqui destrinchados, e do fundo documental ao qual pertencem, procura funcionar como um estudo de caso do tipo de abordagem crítica que acreditamos ser bastante útil na leitura de documentos coloniais cuja autoria e lugar de produção sejam dúbios, mas que continuam a ser frequentados por historiadores em busca de pistas sobre a sociedade colonial.

\section{Fontes manuscritas}

CARTA do governador da capitania de Pernambuco ao Rei sobre a ordem para que todos os ministros, oficiais de justiça e fazenda, governador, Senado e todos os terços de Recife e Olinda participem dos festejos da Restauração. Arquivo Histórico Ultramarino, AHU_ACL_CU_015, cx, 31, D. 2849. Pernambuco, 18 de julho de 1725.

CARTA dos oficiais da câmara de Igarassú ao rei, d. João $V$, pedindo ordem para fazer ação de graças pela Restauração da capitania de Pernambuco do poder dos holandeses, como se faz anualmente em Olinda, no dia 27 de janeiro. AHU_ACL_CU_015, cx, 59, D 5054.

LIVRO de registros, cartas, provisões e ordens régias da Câmara municipal da Cidade de Olinda de 1696. Arquivo Público Jordão Emerenciano -APEJE. D-III 1, fl. 48, 48v; 63v; 66; 71,73; 153; 263-280.

\section{Referências bibliográficas}

ACIOLI, Vera Lúcia. A escrita no Brasil Colônia. Recife: Massangana, 1994.

ANDRADE, Elias Alves de. Aspectos paleográficos em manuscritos dos séculos XVIII e XIX. Filologia e Linguística Portuguesa, São Paulo, n. 10-11, p. 149-172, 2008/2009. 
BARRETO, Josenilce Rodrigues de Oliveira; QUEIROZ, Rita de Cássia Ribeiro de. Edição Semidiplomática e Estudo Lexicológico de dois Autos de Partilha dos Séculos XIX e XX. In: CONGRESSO NACIONAL DE LINGUÍSTICA E FILOLOGIA, 15., 2011, Rio de Janeiro. Cadernos do CNLF. Rio de Janeiro, v. XV, n. 5, t. 1, p. 514-515, 2011.

BARROS, José D'Assunção. A fonte histórica e seu lugar de produção. Cadernos de Pesquisa, Uberlândia, v. 25, n. 2, p. 407-429, jul./dez. 2012.

BENNASSAR, Bartolomé. La monarquia española de los Austrias: conceptos, poderes y expresiones sociales. Salamanca: Ediciones Universidad de Salamanca. 2006.

DURANTI, Luciana. Diplomática: novos usos para uma antiga ciência (Parte V). Acervo, Rio de Janeiro, v. 28, n. 1, p. 196-215, jan./jun. 2015.

ENNES, Ernesto. As guerras nos Palmares: subsídios para a sua história. São Paulo: Companhia Editora Nacional, 1938. v. 1, Domingos Jorge Velho e a Tróia Negra: 1687-1709.

FONSECA, Maria Cristina de Assis Pinto. A escrita oficial: manuscritos paraibanos dos séculos XVIII e XIX. In: PG LETRAS 30 ANOS, 2006. Anais..., v. I, n. 1, p. 570-582, 2006.

FRAGOSO, João; BICALHO, Maria Fernanda; GOUVÊA, Maria de Fátima (Orgs.). O Antigo Regime nos trópicos: a dinâmica imperial portuguesa (séculos XVI-XVIII). Rio de Janeiro: Civilização Brasileira, 2001.

FURTADO, Júnia Ferreira. Desfilar: a procissão barroca. Revista Brasileira de História, São Paulo, v. 17, n. 33, p. 251-279, 1997.

LISBOA, Breno Vaz. Cuidando do patrimônio da Coroa: as contas da Câmara Municipal de Olinda na segunda metade do século XVII e na primeira metade do século XVIII. Saeculum, João Pessoa, n. 29, p. 421-436, jul./dez. 2013.

MARAVALL, J. A. A cultura do barroco: análise de uma estrutura histórica. São Paulo: Edusp; Imprensa Oficial, 1997. 
NOGUEIRA, Gabriel Parente. Fazer-se nobre nas fímbrias do império: práticas de nobilitação e hierarquia social da elite camarária de Santa Cruz do Aracati (1748-1804). 2010. Dissertação (Mestrado em História Social) - Programa de Pós-Graduação em História, Universidade Federal do Ceará, Fortaleza, 2010.

OLIVEIRA, Ricardo de. Amor, amizade e valimento na linguagem cortesã do Antigo Regime. Tempo, Niterói, v.11, n. 21, p. 97-120, jun. 2006.

QUEIROZ, Rita de Cássia Ribeiro de. Documentos manuscritos baianos dos séculos XVIII ao XX: história e fonte de pesquisa. In: CONGRESSO NACIONAL DE LINGUÍSTICA E FILOLOGIA, 15., 2011, Rio de Janeiro. Cadernos do CNLF. Rio de Janeiro, v. XV, n. 5, t. 1, p. 473-484, 2011.

QUEIROZ, Rita de Cássia Ribeiro de. Edição semidiplomática e estudo lexicológico de dois autos de partilha dos séculos XIX e XX. In: CONGRESSO NACIONAL DE LINGUÍSTICA E FILOLOGIA, 15., 2011, Rio de Janeiro. Cadernos do CNLF. Rio de Janeiro, v. XV, n. 5, t. 1, p. 514-515, 2011.

QUINTANEIRO, Tania. Um toque de clássicos: Marx, Durkheim e Weber. Belo Horizonte: Ed. UFMG, 2002.

SALGADO, Graça (Coord.). Fiscais e meirinhos: a administração no Brasil colonial. Rio de Janeiro: Nova Fronteira, 1985.

SANTIAGO, Camila Fernanda Guimarães. As festas promovidas pelo senado da Câmara de Vila Rica (1711-1744). 2001. Dissertação (Mestrado em História) - Faculdade de. Filosofia e Ciências Humanas, Universidade Federal de Minas Gerais, Belo Horizonte, 2001.

SILVA, Kalina Vanderlei. De ganhadores, bandidos, soldados e festas: o cotidiano nas ruas das cidades açucareiras de Pernambuco nos séculos XVII e XVIII. In: GANDRA, Edgar; POSSAMAI, Paulo (Orgs.). Estudos de história do cotidiano. Pelotas-RS: Ed. da UFPel, 2011a. v. 1, p. 63-85.

SILVA, Kalina Vanderlei. Festa e memória da elite açucareira no século XVII: a Ação de Graças pela Restauração da Capitania de Pernambuco contra os holandeses. In: OLIVEIRA, Carla Mary S.; MENEZES, Mozart Vergetti de; GONÇALVES, Regina Célia (Orgs.). Ensaios sobre a América Portuguesa. João Pessoa: Editora Universitária UFPB, 2009. 
SILVA, Kalina Vanderlei. O herói virtuoso, prudente e dissimulado: o cortesão como ideal masculino nas cortes ibéricas dos séculos XVI E XVII. História, São Paulo, v. 32, p. 231-250, 2013.

SILVA, Kalina Vanderlei. O Recife em festa e a disputa pela representação do Império: o conflito de jurisdição entre Recife e Olinda pela festa de Corpus Christi no Século XVIII. In: SCHURSTER, Karl; SILVA, Giselda Brito (Orgs.). Histórias do Recife, narrativas do passado e interpretações do presente. Rio de Janeiro: Luminária Acadêmica, 2011b. v. 1, p. 76-93. SILVA, Welber Carlos Andrade da. As elites de Santo Antônio: poder, representações e sociabilidade - o caso da Irmandade do Santíssimo Sacramento (1791-1822). 2012. Dissertação (Mestrado em História Social da Cultura Regional) - Departamento de História, Universidade Federal Rural de Pernambuco, Recife, 2012.

SOUZA, George Felix Cabral de. Elite y ejercicio de poder em el Brasil colonial: la Cámara Municipal de Recife (1710-1822). 2007. Tese (Doutorado em História) - Faculdad de Geografia e Historia, Universidad de Salamanca, Salamanca, 2007.

VASCONCELOS, Suani de Almeida. Carta de Sesmaria: século XIX: edição semidiplomática e estudo histórico. Scripta Philológica, Feira de Santana, n. 1, 2005.

WEBER, Max. Economía y sociedad: esbozo de sociologia comprensiva. México: Fondo de Cultura Económica, 2002.

Recebido em setembro de 2015.

Aprovado em junho de 2017. 